\title{
- Capturing temporary populations: assessing the utility of Facebook in the 2019 flood in Townsville, Australia
}

\author{
Chiu-San Chen* The University of Queensland \\ Radoslaw Panczak The University of Queensland \\ Alexander Whitehead The University of Queensland \\ Jonathan Corcoran The University of Queensland
}

* Email: chiusan.chen@uq.net.au. Address: Queensland Centre for Population Research, School of Earth and Environmental Sciences, Chamberlain Building, The University of Queensland, St Lucia, Qld 4072, Australia.

Paper received 20 May 2020; accepted 30 October 2020; published 16 November 2020

\section{Introduction}

Each year, more than 200 million people are impacted by natural hazards worldwide that result in displacement, the financial loss of US\$200 billion, and more than 20,000 lives lost (UNISDR 2015). In response, mitigation strategies such as risk-reducing infrastructure (e.g. coastal embankment) have significantly reduced natural hazard-induced casualties worldwide (Kellet and Sense 2014). Yet timely evacuation or rescue in hazards (e.g. earthquakes, flash floods) have remained a persistent difficultly due to the lack of real-time information on the number and location of impacted populations (Kobayashi et al. 2011).

Accurate and timely estimations of temporary population have historically been difficult due to the absence of data at sufficiently high spatiotemporal resolutions (Hugo and Harris 2013). With the advent of non-traditional sources including data derived from mobile phones (Chen et al. 2018), mobile phone applications (Corcoran et al. 2018), and social media (Gong et al. 2018), each represents new candidates from which to estimate temporary populations at a geography and timing that has utility for hazard management and recovery.

\section{Data and methods}

Here we focus on an emergent data source, Facebook, and examine its utility to track temporary populations. More specifically, we scrape estimated average user data from the Facebook Ads Manager and spatially integrate this with information on water levels from the Bureau of Meteorology (BOM). The resulting graphic (Figure 1) visualises the changes in estimated average Facebook users and the maximum water level across for Townsville and surrounds during the flood that took place in early 2019. 


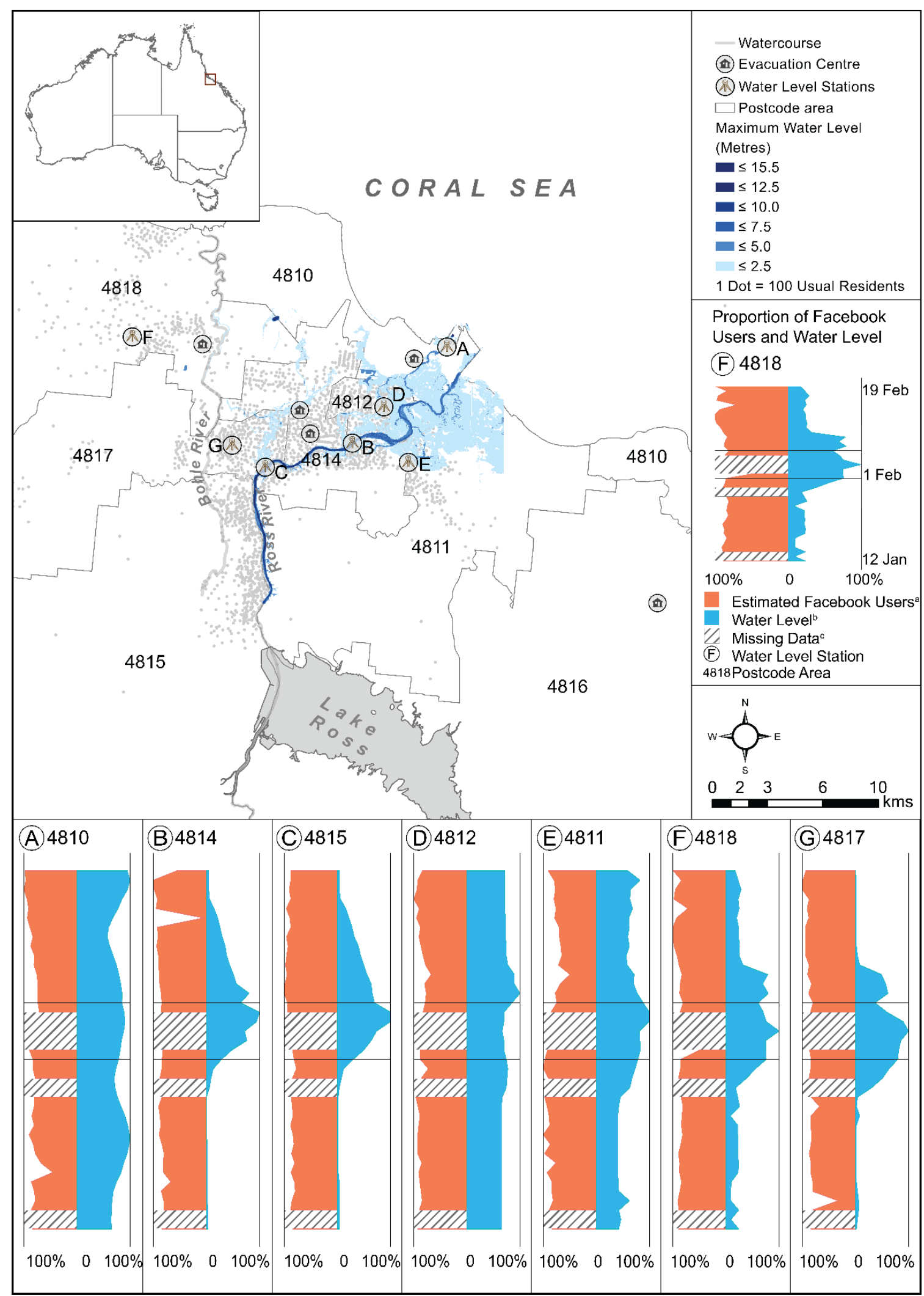

Figure 1: Changes in estimated Facebook users and changes in the water level during the 2019 Townsville Flood in Queensland, Australia

Notes: (a) The maximum recorded number of estimated Facebook users for a given postcode is given by '100\%'. (b) The maximum water level recorded at water level stations closest to a given postcode is given by '100\%'. (c) Facebook records are missing for 13th and 27th January, and 1st to 3rd February (ABS 2017; BOM 2019; Townsville City Council 2019). 


\section{Key features}

The population at risk and temporary population mobility is successfully captured within the most severely impacted locales around the Central Business District (postcodes 4812 and 4814), displaying prolonged shifts in temporary population numbers, possibly an outcome of recovery efforts. Less dramatic changes in population numbers are found across the inland areas that are more distant from the Ross River. Interestingly, we also detect shifts in population numbers for postcode areas that have an operational evacuation centre located within their boundaries. Nevertheless, the fragility of missing data, the relatively coarse spatial resolution of the postcode, along with the undisclosed algorithm employed to generate population counts place a question mark on the reliability of Facebook data to examine temporary populations. As real-time population mobility dynamics are central in hazard response and rescue, the application of Facebook data should, therefore, be cautiously treated and accompanied by other sources of data. In summary, we assessed the extent to which a non-traditional source of data (Facebook) can capture the population at risk and temporary population mobility dynamics, along with developing a novel visual analytic to enhance our understanding of temporary population mobility in the context of natural hazards.

\section{Ethics approval}

Ethics approval was given by The University of Queensland. Project: "Estimating temporary populations - 08/06/2020 AMENDMENT" (\#2017001323).

\section{References}

Australian Bureau of Statistics (2017) Census of Population and Housing: Mesh Block Counts, Australia, 2016. Catalogue No. 2074.0. Canberra: ABS.

Bureau of Meteorology (2019) Queensland rainfall and river height data. http://www.bom.gov.au/gld/flood/rain river.shtml. Accessed 17 March 2019.

Chen J, Pei T, Shaw S-L, Lu F, Li M, Cheng S, Liu X \& Zhang H (2018) Fine-grained prediction of urban population using mobile phone location data. International Journal of Geographical Information Science 32(9): 1770-1786.

Corcoran J, Zahnow R and Assemi B (2018) Wander: A Smartphone App for Sensing Sociability. Applied Spatial Analysis and Policy 11(3): 537-556.

Gong V, Yang J, Daamen W, Bozzon A, Hoogendoorn S \& Houben G-J (2018) Using social media for attendees density estimation in city-scale events. IEEE Access 6: 36325-36340.

Hugo G J and Harris K R (2013) Time and tide: moving towards an understanding of temporal population changes in coastal Australia. The University of Adelaide, Adelaide. http://www.esc.nsw.gov.au/living-in/about/community-profile-and-populationforecasts/sea change taskforce report 29 april 2013.pdf. Accessed 19 March 2019.

Kellet J and Sense P (2014) Call to Action: Disaster Risk Reduction Makes Development Sustainable. New York: United Nations Development Programme.

Kobayashi T, Medina R M and Cova T J (2011) Visualizing diurnal population change in urban areas for emergency management. The Professional Geographer 63(1): 113-130.

Townsville City Council (2019) Ross River $2000 \mathrm{~m}^{3}$ /s Flood Depth. Unpublished data, Townsville City Council.

United Nations International Strategy for Disaster Reduction (2015) The Human Cost of Weather Related Disasters - 1995-2015. Geneva: UNISDR, CRED. 